\title{
FLIPPED LEARNING AND DISTANCE LEARNING: POSSIBLE COMBINATION IN A UNIVERSITY EXPERIENCE
}

\author{
Federica Baroni \\ University of Bergamo, Department of Human and Social Sciences, Piazzale Sant'Agostino 2 - I-24129 Bergamo, Italy
}

\begin{abstract}
The work describes a university experience of distance learning imposed by the health emergency in which, as part of the "Methodologies and teaching in early childhood" course for the training of future educators, a Flipped Learning approach with the support of telematic technologies has been tested with 381 students. The methodologies used will be described, with reference to the theoretical principles of active and collaborative teaching. Through the data collected by a questionnaire addressed to the participants, the results of the experiment will be reported in terms of students' perception of the learning and the dynamics of the relationship with the teacher and colleagues in the course.
\end{abstract}

\section{KEYWORDS}

Flipped Learning, e-Learning, Active Teaching Methodologies, University Education, Student Perceptions

\section{INTRODUCTION}

At the time of the COVID-19 emergency, which has been affecting Italy since February 2020 and is still distorting the traditional ways of living, working and studying, universities are called upon to remotely transfer teaching activities without failing in the task of training and producing culture.

As part of the "Teaching and Learning" course for second year Education Sciences students at the University of XXX, a teaching method has been tested with active methodologies inspired by the Flipped Classroom model (Bergmann and Sams, 2012). The degree course is aimed at educators in early childcare services and intends to train professional figures capable of accompanying the development of boys and girls and of knowing, promoting and enhancing specific educational interventions aimed at the full development of their personalities: for the 20/21 AY approximately 550 students are registered in the second year; among these, 478 were enrolled in two Teams on the Microsoft Teams platform with which the university course in question was provided, entirely remotely due to the COVID emergency, which for the "Methodologies and teaching in early childhood" module included 34 hours of lessons and workshop activities between the 5th of October and the 12th of November 2020. Among the general objectives of the course: define the concept of teaching; recognize the existing correlations between teaching and the anthropological and learning concept that it conveys; understand strategies for the development of teaching with reference to the main collaborative and cooperative forms of organisation of educational and teaching activities, explore methodological and technological approaches for teaching; acquire scientific vocabulary in relation to the teaching content. In addition to the Teams platform, for lectures in synchronous mode and the archiving of video recordings to facilitate working students or students with real-time connection difficulties, university lecturers have access to the Moodle platform for e-learning course management.

It is now accepted that distance learning is not the online reproduction of presence and that, in addition to the technological aspects, it is necessary to consider the quality elements of (distance) teaching (García-Peñalvo, 2008), which teachers are called upon to experiment with through different methodologies. Among these, the active didactics of the Flipped Classroom which, to encourage student learning: 1) modifies time management inside and outside the classroom 2) provides for different ways of acquiring knowledge and skills 3) facilitates interaction between peers and with the teacher 4) uses technologies to facilitate the process (Hwang et al., 2015). 


\section{THE EXPERIENCE}

The direct objectives of the experience were to encourage active participation in the course by students, to support their interests, to enhance the professional and extra-academic experiences of the participants and to keep the topics of the course open; the indirect objective was to experiment with an active teaching methodology (in e-learning) to make it the subject of ex-post reflection and discussion. After introductory theoretical lessons on the themes of didactic planning and early childhood education, students were invited to participate in a project divided into three phases. Participation was optional and provided for the availability to work in self-managed groups formed of 3 to 6 members maximum: 381 students took part, divided into 90 groups.

\subsection{Stage 1: Introduction of Themes}

Through computer-mediated brainstorming techniques (Dennis and Valacich, 1993) - with the microphone, chat and show of hands functions of Microsoft Teams - the students, with the teacher as facilitator (Thorpe, 2002), identified 26 project macro-themes which had interest for the 0-6 year age group and the didactic perspective as constraints: sensorial education, emotional education, interculture, outdoor education, bilingualism, nursery school, music education, theatre, art, language development, children's literature, non-verbal communication, psychomotricity, parenting, team building, environmental education, nutrition education, clown therapy, acclimatisation to nursery, pedagogy of freedom, pet therapy, corporate nurseries, schools without backpacks, Reggio Emilia approach, inclusion, childcare services abroad.

The students were therefore asked to independently form interest groups and to register via an online questionnaire by communicating a project title to be placed in one of the 26 macro-themes.

\subsection{Stage 2: Group Work}

The groups worked independently, outside class time, to focus on the chosen theme and deepen the related topics both from a theoretical point of view (research of sources, analysis of documents, etc.) and from a practical point of view, with the possibility of proposing or documenting educational and didactic activities aimed at children aged 0 to 6 . The objectives of this stage were to encourage remote collaborative work, to initiate simple research paths, to encourage discussion and the sharing of experiences among students.

\subsection{Stage 3: Presentation and Discussion}

Over the next 3 weeks, each group publicly presented their work in the dedicated 10/15 minutes. The Teams platform's virtual classroom tools allowed student speakers to show themselves on webcam, speak via the microphone, share their screen, interact in real time with colleagues via chat. Although it was not mandatory, all 90 groups chose to make use of multimedia presentation tools (PowerPoint and Prezi) to facilitate the presentation and make the exemplification of concrete teaching actions and proposals more effective. The presentations showed videos of direct experiences in childcare services, interviews with experts and witnesses, photographs of materials, environments, and activity-related settings. The web was the main source of information gathering, also due to the closure of local libraries and the strict limitation on travel imposed by the lockdown. The students shared materials and references used on the course's Moodle platform, giving colleagues the possibility of future insights. At the end of each lesson dedicated to the presentation of the works, the teacher encouraged discussion with questions, requests for clarification, narration of experiences, inviting participants to do the same.

\section{RESULTS AND DISCUSSION}

At the end of the course, an online questionnaire was proposed to help gather students' perceptions of the effectiveness of the methodology tested, as previously tested in the literature (Roach, 2014; Sohrabi and Iraj, 2016; Sletten, 2017). The anonymous questionnaire was addressed to all students and divided into two 
sections that distinguished between respondents participating in the activity of the groups and non-participants. Of the 307 respondents, $99.3 \%$ are women (in line with the Degree Course with a strong female characterization), $87.3 \%$ are at least 25 years old; $9.8 \%$ are age $25-35 ; 2 \%$ are age $35-45 ; 30.9 \%$ were working in education while taking classes. With reference to professional experience, $40.7 \%$ of the students have never worked in education; $13 \%$ have been working in the sector for less than a year; $27.4 \%$ have between 1 and 3 years of experience; $11.4 \%$ between 3 and 6 years; 7.5\% more than 6 years. The questionnaire proposes a first section with 7 statements to which everyone had to respond by selecting from 5 degrees of agreement (strongly agree, agree, undecided, disagree, completely disagree). The second section, on the other hand, is dedicated to those who carried out the group work and consists of 6 statements to be evaluated according to the same scale of agreement (271 out of 307 answered. $88.2 \%$ ). The statements partly contain elements characterising the Flipped Learning (FL) approach (Akçayır and Akçayır, 2018) to evaluate the perception of effectiveness by the students involved, without, however, making explicit reference to the teaching methodology being investigated: e.g. "the workshop method encouraged the active participation of the students"; "the topics covered by colleagues in the group work were stimulating"; "the projects presented by my colleagues allowed me to discover new things"; "the role of the teacher as mediator is enhanced by the proposed teaching method"; "[the group work] allowed me to experiment with research actions and tools (definition of focus, searching for sources, etc.)", "[the group work] fostered cooperation and discussion with colleagues".

Since this is an entirely remote course, some items also investigate students' perception of the use of technologies: "the workshop method (group work) facilitated the use of the course in remote mode", "[the group work] has increased my digital skills". An open question, not mandatory, on the opportunities and challenges of the proposal ends the questionnaire.

The proposal was positively received by students who express the most favourable opinions on the opportunity for active participation and discussion/cooperation between colleagues. The role of the teacher as a guide was also understood by the students, as in previous works that have investigated this aspect (McLean and Attardi, 2018).

In general, in the perception of the students, the course has increased knowledge $(86.9 \%$ strongly agree/agree; $12 \%$ undecided) and offered useful ideas for the study path $(90.5 \%$ strongly agree/agree; $8.4 \%$ undecided); the workshop method facilitated the fruition of the distance course (79.4\% strongly agree/agree; $14.6 \%$ undecided; $5.8 \%$ disagree) and favoured the active participation of the students $(88.5 \%$ strongly agree/agree; $8.4 \%$ undecided; $2.9 \%$ disagree). $92.5 \%$ of respondents feel that they have received interesting stimuli from colleagues and have discovered new things from the work of other students $(96.7 \%$ strongly agree/agree). In addition, $86.3 \%$ believe that the teaching method proposed has enhanced the role of the teacher as a mediator.

For students who took part in group activities, the method increased their knowledge (95.5\% strongly agree/agree; $2.2 \%$ undecided; $2.2 \%$ disagree) and allowed them to experiment with teaching activities and tools for children (95.2\% strongly agree/agree; $2.5 \%$ undecided; $1.4 \%$ disagree). Less awareness, on the other hand, is noted on the increase in research skills ( $88.1 \%$ strongly agree/agree; $9.9 \%$ undecided; $1.1 \%$ disagree) and on digital skills (71.9\% strongly agree/agree; $19.1 \%$ undecided; $8.1 \%$ disagree). Interesting results emerge from the perception that this method has enhanced the students' work and extra-university experience (79.7\% strongly agree/agree; 14\% undecided) and encouraged cooperation and discussion with colleagues (96.3\% strongly agree/agree).

Among the challenges expressed in the qualitative section of the questionnaire: poor collaboration between colleagues in preparing group work ( 2 students), excessive duration of the presentation phase of the works (1), little time to comment on group work (1), little interaction between people (1), workshop activity not compatible with distance learning (2), difficulties for those with no experience in the educational field (1). Among the strengths: opportunities to reflect on daily practice with children (2) and try out direct teaching experiences (1), ease of presenting oneself in person, without presentation anxiety (1). 


\section{CONCLUSIONS}

The conduct of the activities and the survey of the students' opinions through a questionnaire at the end of the experience made it possible to focus on the opportunities and challenges of the proposed methodology: the attempt to change the habits of traditional teaching (largely frontal) and to increase the active participation of students, also through cooperative learning, was understood and appreciated by the majority. The teacher played the role of organizer in the early stages, of technical tutor in the management of the platforms and of activator of the discussion dynamics between students. As has already emerged in the literature, such proposals support motivation to learn, encourage critical thinking and increase the group's sense of self-efficacy (Chang and Hwang, 2018).

The presentation of the group work, sometimes lacking in the quality of the proposed multimedia materials, has highlighted the need to support students' digital skills in order to offer them opportunities for reflection and exercise on the principles of multimedia communication, also from the perspective of learning (Mayer, 2005). The methodology has made it possible to highlight that elements of research methodology and the correct use of sources must also be strengthened, important aspects both for the academic career and for the educational professionalism that students must acquire at the end of the degree course.

Some questions on how to encourage the interaction of students on the Net more in practice and how to connect the extra-university experience to the activities of distance learning remain open: this work opens up subsequent experiments that refine the proposed methodology and is part of the debate on the FL approach in the academic field (Al-Samarraie et al., 2020), where the high numbers of students and the hourly schedule of lessons, often condensed into a few weeks, represent an important constraint.

\section{REFERENCES}

Akçayır, G. and Akçayır, M., 2018. The flipped classroom: A review of its advantages and challenges. Computers \& Education, Vol. 126, No. 1, 334-345.

Al-Samarraie, H. et al., 2020. A flipped classroom model in higher education: a review of the evidence across disciplines. Educational Technology Research and Development, Vol. 68, 1017-1051.

Bergmann, J. and Sams, A., 2012. Flip Your Classroom. Reach Every Student in Every Class Every Day. ISTE, Washington DC.

Chang, S. C. and Hwang, G. J., 2018. Impacts of an augmented reality-based flipped learning guiding approach on students' scientific project performance and perceptions. Computers \& Education, Vol. 125, 226-239.

Dennis, A. R. and Valacich, J. S., 1993. Computer Brainstorms: More Heads Are Better than One. Journal of Applied Psychology, Vol. 78, No. 4, 531-37.

García-Peñalvo, F. J., 2008. Advances in E-Learning: Experiences and Methodologies. Information Science Reference, Hershey, PA.

Hwang, G. et al., 2015. Seamless flipped learning: a mobile technology-enhanced flipped classroom with effective learning strategies. Journal of Computers in Education, Vol. 2, 449-473.

Mayer, R., 2005. The Cambridge Handbook of Multimedia Learning. Cambridge University Press, New York.

McLean, S. and Attardi, S. M. 2018. Sage or guide? Student perceptions of the role of the instructor in a flipped classroom. Active Learning in Higher Education. doi: 10.1177/1469787418793725.

Roach, T., 2014. Student perceptions toward flipped learning: New methods to increase interaction and active learning in economics. International Review of Economics Education, Vol. 17, 74-84.

Sletten, S.R., 2017. Investigating Flipped Learning: Student Self-Regulated Learning, Perceptions, and Achievement in an Introductory Biology Course. Journal of Science Education and Technology, Vol. 26, No. 3, 347-358.

Sohrabi, B. and Iraj, H., 2016. Implementing flipped classroom using digital media: A comparison of two demographically different groups perceptions. Computers in Human Behavior, Vol. 60, 514-524.

Thorpe, M., 2002. Rethinking Learner Support: The challenge of collaborative online learning. Open Learning: The Journal of Open, Distance and e-Learning, Vol. 17, No. 2, 105-119. 